case reports. McNicol and Smith (1964) reported on 15 patients with hypothermia, all of whom had raised blood urea levels; and in five out of eight cases described by Fruehan (1960) there was a pronounced decrease in urine output 12 to 24 hours after admission.

The beneficial effects of hypothermia on the preservation of renal function after transplantation are recorded (Schloerb, et al., 1959; Calne, et al., 1963) and hence the impairment of renal function that occurs after accidental exposure may be related to periods of relative ischaemia during rewarming.

The histological shanges reported here suggest that the renal failure was a direct result of ischaemic damage to the kidneys. Renal damage complicating accidental hypothermia may result not from the hypothermia itself but may occur as the body temperature is increased, suggesting that plasma expanders and mannitol should be used more vigorously during the rewarming phase.

\section{Case of Lipodystrophy}

\section{British Medical fournal, 1970, 2, 464}

It seems likely that lipodystrophy is a disease of great antiquity, since Pharaoh Amenophis IV is claimed to have shown its distinctive clinical features (Ameline and Quercy, 1920). There is loss of body fat which is most conspicuous in the subcutaneous tissues. The affected areas show a distinct line of demarcation from normal fat and the line follows a dermatome distribution. No previous report has been found, however, of a case where there was fat loss affecting localized areas of individual dermatomes with normal fat both above and below these areas. Such a case is reported here.

\section{CASE Report}

A 65-year-old housewife first attended in 1956 when she was found to be suffering from diabetes mellitus and thyrotoxicosis. These conditions were controlled initially by insulin therapy and subtotal thyroidectomy respectively and she remained well until 1960. From then on she required treatment with thyroxine sodium, owing to the occurrence of hypothyroidism. In March 1968 she complained of "holes" in her abdomen and legs. Clinical examination showed loss of subcutaneous fat in three areas: right lower abdominal wall, an area $1 \frac{1}{2}$ in. $(3.8 \mathrm{~cm}$.) in the sagittal plane by 3 in. $(7.6 \mathrm{~cm}$.) in the transverse plane; left lower abdominal wall, an area $1 \frac{1}{2}$ by 2 in. $(3.8$ by $5 \mathrm{~cm}$.); and right thigh, an area $1 \frac{1}{2}$ by $2 \frac{1}{2}$ in. $\left(3.8\right.$ by $6.4 \mathrm{~cm}$.). A further lesion $\frac{1}{4}$ in. $(0.6 \mathrm{~cm}$.) diameter was seen in the right heel.

The areas on the abdomen and thighs corresponded to the skin distribution of the first lumbar segment and the area on the heel to the first sacral segment. The only positive finding in the investigations carried out was high titres of thyroid autoantibodies, suggesting Hashimoto's autoimmune thyroiditis (Goudie et al., 1959). The lesions had not progressed at the time of this report, and because of their obviously benign nature no therapeutic measures has been undertaken.
W. I. MCKEAN, M.B., CH.B., M.R.A.C.P., Medical Registrar.

S. R. DIXON, M.B., CH.B., M.R.A.C.P., Research Fellow.

J. F. GWYNNE, M.D., M.R.C.PATH., M.C.P.A.,

R. O. H. IRVINE, M.D., P.R.A.C.P., M.R.C.P., Associate Professor of Medicine.

Medical School, University of Otago,

Dunedin, New Zealand.

\section{REFERENCES}

Calne, R. Y., Pegg, D. E., Pryse-Davies, J., and Brown, F. L. (1963). British Medical fournal, 2, 651 .

Fruehan, A. E. (1960). Archives of Internal Medicine, 106, 218.

McNicol, M. W., and Smith, R. (1964). British Medical fournal, 1, 19.

Schloerb, P. R., Waldorf, R. D., and Welsh, J. S. (1959). Surgery, Gynecology and Obstetrics, 109, 561.

\title{
COMMENT
}

There is little doubt that this was a case of lipodystrophy. The possibility that the lesions were areas of fat atrophy due to the local injection of insulin was dismissed for three reasons. The patient declared that insulin had never been injected at any of these sites; her regular injection sites were unaffected; and it is difficult to imagine the heel being used as an insulin injection site.

The most widely held view is that lipodystrophy represents an endocrine failure, and support for this is derived from the sex incidence and the close association of the disease with various other types of endocrine disease. Females predominate in all series in a ratio of 4 to 1 , and lipodystrophy occurs mainly during the peaks of incidence of endocrine disease. We would suggest that lipodystrophy is an autoimmune disorder. Support for this is gained here by the occurrence of Hashimoto's thyroiditis, an autoimmune disease (Anderson, 1964), as well as diabetes mellitus. This latter, if not itself autoimmune in aetiology, is significantly associated with other autoimmune conditions (Becket and Matthews, 1962; Arapakis et al., 1963). All these conditions are known to have a pronounced tendency to familial occurrence.

I would like to thank Dr. L. D. W. Scott for permission to publish this case and Dr. R. Hume for his help in preparing the manuscript.

P. J. ROONEY, M.B., CH.B.

Department of Medicine, Southern General Hospital, Glasgow S.W.1.

Ameline, M., and Quercy, P. (1920). Revue Neurologique, 27, 448. Anderson, J. R. (1964). British Medical Bulletin, 19, 251.

Arapakis, G., Bock, O. A. A., Williams, D. L., and Witts, L. J. (1963) British Medical fournal, i, 159 .

Becket, A. G., and Matthews, D. M. (1962). Clinical Science, 23, 361. Goudie, R. B., Anderson, J. R., and Gray, Kathleen G. (1959). Fournal of Pathology and Bacteriology, 77, 389. 